\title{
Patlıcanda (Solanum melongena L.) Mikrospor Kültürü Üzerine Bir Ön Araştırma
}

\author{
Buse ÖZDEMİR ÇELİK${ }^{1}$, Ahmet Naci ONUS ${ }^{* 2}$ \\ 1,2Akdeniz Üniversitesi, Ziraat Fakültesi, Bahçe Bitkileri Bölümü, 07058, Antalya \\ ${ }_{1}^{1}$ (ORCID: https://orcid.org/0000-0002-5108-8124) \\ 2(ORCID: http://orcid.org/0000-0001-8615-1480)
}

(Alınıș / Received: 06.06.2018, Kabul / Accepted: 29.01.2019, Online Yayınlanma / Published Online: 11.03.2019)

\section{Anahtar Kelimeler}

Patlican,

Mikrospor kültürü,

Haploid,

DH,

Mikrospor embriyogenesis
Özet: Mikrospor embriyogenesis olgunlaşmamış erkek gametofitlerin in vitro kültür süresince gametofitik gelişimden embriyo oluşturmak üzere uyarıldığı bir sistemdir. $\mathrm{Bu}$ araştırmada, iki adet patlıcan (Solanum melongena L.) çeşidinin mikrospor kültür tekniğine tepkisinin belirlenmesi amaçlanmıștır. Bu amaçla, ilk olarak uygun mikrospor gelişme dönemindeki mikrosporlar (çoğunluğu vakuol mikrospor ve genç çift çekirdekli polen) anterlerden izole edilerek $35^{\circ} \mathrm{C}^{\prime}$ de 3 gün karanlık koşullarda ön uygulamaya maruz bırakılmıştır. Ön uygulama işleminden sonra mikrosporlar \%2 sakkaroz, $0.5 \mathrm{mg} / \mathrm{l}$ naphthaleneacetic acid (NAA) ve 0.5 mg/l 6-benzylaminopurine (BAP), pH 5.9, içeren NLN ortamında kültüre alınmış ve bir ay boyunca $25^{\circ} \mathrm{C}$ de karanlıkta bekletilmiştir. Kültür süreci boyunca mikrospor embriyogenesis indüksiyon süreci mikroskobik olarak analiz edilerek bu gelişimsel sapmanın ilk evrelerine odaklanılmıştır. Mikrosporların indüksiyondan hemen sonra kallus haline gelmeden önce simetrik bölünme ve çok çekirdekli yapılar meydana getirdiği daha sonra ise mikrosporların direkt embriyo oluşturmadıkları ve kallus oluşturduğu tespit edilmiştir. Araştırmada bir ay sonunda mikrosporlardan yalnızca kallus oluşumu meydana gelmiştir ve petri başına toplam kallus sayısı belirlenmiştir. G07-1 çeşidinde ortalama 288 kallus/petri elde edilirken G07-2 çeşidinde 64 kallus/petri meydana gelmiştir. Bu araştırmanın mikrospor kültürü tekniğinin geliștirilebilmesi üzerine hem uygulamalı, hem de temel araştırmalar için yol gösterici olacağı düşünülmektedir.

\section{A Preliminary Research on Microspore Culture in Eggplant (Solanum melongena L.)}

\section{Keywords}

Eggplant,

Microspore culture,

Haploid,

DH,

Microspore embryogenesis

\begin{abstract}
Microspore embryogenesis is a process in which immature male gametophytes are induced to divert them from their gametophytic pathway toward embryo development during in vitro culture. In this study, therefore, it was aimed to determine the response of two eggplant cultivars to microspore culture. For this purpose, the microspores were firstly isolated from the anthers at the appropriate stage of microspore development (containing mostly vacuolate microspores and young bicellular pollen) and subjected to pre-treatment at $35^{\circ} \mathrm{C}$ for 3 days in dark conditions. After pre-treatment, the microspores were cultured in liquid NLN culture medium supplemented with $2 \%$ sucrose, $0.5 \mathrm{mg} / \mathrm{l}$ naphthaleneacetic acid (NAA), and $0.5 \mathrm{mg} / \mathrm{l}, 6$-benzylaminopurine (BAP), pH 5.9, and kept in the dark at $25^{\circ} \mathrm{C}$ for one month. During this culture process, the microspore embryogenesis induction was microscopically analyzed and focused on the initial stages of this developmental process. Immadiately after induction, before the microspores develop into callus, they were induced to divide symmetrically and form multinucleated structures, and then microspores did not form direct embryos and formed callus. At the end of one month, only callus formation occurred from microspores and total callus number per petri was analyzed. The average calli for G07-1 cultivars was 288 calli/petri, while it was 64 calli/petri dish for G07-2 cultivars. It is thought that this research will guide both practical and basic researches on the development of microspore culture technique.
\end{abstract}




\section{Giriş}

Double haploid (DH) teknolojisi hibrit tohum üretimi için gerekli homozigot saf hatların tek bir generasyonda elde edilmesine olanak sağlaması ve ıslah programlarını hızlandırması nedeniyle klasik ıslah tekniklerine bir alternatif olușturmaktadır [1, 2, 3]. DH bitkileri elde etmenin en etkili yollarından birisi de mikrospor embriyogenesistir.

Mikrospor embriyogenesis olgunlaşmamış erkek gametofitlerin in vitro kültür süresince anter kültürü veya mikrospor kültürü yöntemleri kullanılarak gametofitik gelişimden embriyo oluşturmak üzere uyarıldığı bir sistemdir. Mikrospor kültüründe haploid bitkiler mikrosporlardan elde edilen embriyolardan direkt olarak veya mikrosporlardan elde edilen kalluslardan organogenesis yoluyla indirekt olarak elde edilebilmektedir [4]. Bu haploid embriyolar ya kendiliğinden ya da kromozom katlama maddeleri ile muamele edildikten sonra homozigot DH bitkilere dönüștürülebilmekte ve sslah programlarında kullanılabilmektedir. $\mathrm{Bu}$ olgu angiospermlerde 250 'den fazla tür için tanımlanmıştır [5]. Bunlardan yalnızca kolza (Brassica napus L.), tütün (Nicotiana spp.), arpa (Hordeum vulgare L.) ve buğday (Triticum aestivum L.) olmak üzere dört tanesinin model türler olarak kabul edildiği bildirilmiștir [6]. Ancak Solanaceae familyasına ait türlerde olduğu gibi agronomik olarak önemli olan birçok tür hala mikrospor embriyogenesise karşı inatçıdır ve bunun nedeni hakkında çok az bilgi bulunmaktadır [7].

Patlıcan, Solanum melongena L., Solanaceae ailesinin Solanum cinsine ait diploid $(2 \mathrm{n}=2 \mathrm{x}=24)$ bir sebzedir ve ülkemiz dahil pek çok ülkede ekonomik değere sahiptir. Patlican mikrospor embriyogenesis indüksiyonu için inatçı bir tür olarak görülmekle birlikte DH bitkiler elde etmek mümkündür. Ancak yöntemin etkinliği hala sınırlı derecededir ve indüklenebilir genotip sayısı hala yetersizdir [7]. Mikrospor embriyogenesisle ilgili olarak bazı patlıcan genotiplerinde anter kültürü yoluyla olumlu sonuçlar elde edilmiștir ve anter kültüründen bitki rejenerasyonu üzerine ilk rapor 1973 yıllında yayınlanmıştır [8]. Daha sonraki çalışmalarda da haploid veya DH bitkilerin elde edildiği farklı araştırmacılar tarafından bildirilmiştir [9-14]. İlk raporun yayınlanmasından günümüze kadar anter kültürü için Dumas de Vaulx ve Chambonnet [10] tarafından yayınlanan protokolün modifiye edilerek kullanılmasıyla DH hatlar elde edilmiştir [15-20]. Patlıcanda anter kültürü ile yapılan bazı başarılı çalışmalara rağmen bu yöntemin pratik kullanımını kısıtlayan bir takım dezavantajlar bulunmaktadır $[7,19]$. Anter kültüründeki bu sınırlamaların, mikrosporların doğrudan izolasyonu ve kültüre alınmasıyla aşılabileceği düşünülmektedir. Ancak mikrospor kültürünün sağladığı avantajlara rağmen patlıcanda mikrospor kültürü ile ilgili çok az çalışma bulunmaktadır [21-25]. Mikrospor kültürü tekniği yurt dışında birçok türde islah programlarında başarılı bir şekilde kullanılabilmesine rağmen ülkemizde konu ile ilgili yapılan araştırma sayısının birkaç çalışma dışında son derece sınırlı olduğu tespit edilmiştir [25-30]. Teknikteki başarı türlere ve genotiplere göre farklılık göstermektedir. Patlıcanda mikrospor kültürü üzerine ülkemizde tek çalışma Bal vd. [26] tarafından yapılmış olup araştırmada sadece mikrosporlardan elde edilen çok çekirdekli yapılar rapor edilmiştir. $\mathrm{Bu}$ durum patlıcanda mikrospor kültürünün ülkemizde geliştirilmesi gerekliliğinin açık bir kanıtıdır. Bu çalışmada iki farklı patlıcan çeşidinde mikrosporlar izole edilerek kültüre alınmış ve mikrosporların gelişim seyri incelenmiştir.

\section{Materyal ve Metot}

Araştırmada bitkisel materyal olarak G07-1 ve G07-2 olarak adlandırılmış iki adet tescil aşamasında $F_{1}$ patlıcan çeşidi kullanılmıştır. Sera koşullarında yetiştirilen bitkilerden gelişimin uygun aşamasındaki anterler (çoğunluğu vakuol mikrospor ve genç çift çekirdekli polenleri içeren anterler) belirlenen uzunluklarda dijital kumpas yardımıyla seçilmiştir. Anterler \%70 etanol' de 30 saniye, ardından \%10'luk ticari çamaşır suyunda 5 dakika bekletilerek sterilize edilmiştir (Şekil 1a). Miyoshi [22] tarafından belirtilen protokol göre, sterilizasyondan sonra, anterler steril bidistile suda ezilmiş (Şekil 1b) ve anter dokularına ait içerik, $40 \mu \mathrm{m}$ filtre ile süzülmüs (Şekil 1c) ve $850 \mathrm{rpm}$ de soğutmalı santrifüjde 4 dakika santrifüjlendikten sonra üç kez steril bidistile su ile yıkanmıştır. Mikrospor peleti steril distil su içinde süspansiyon haline getirilmiş ve mililitrede 500000 mikrospor olacak şekilde mikrospor yoğunluğu ayarlanmıştır. Çalışmamızda patlıcanda yapılan mikrospor kültürü çalışmalarında olumlu etkisi bildirilen ilk üç günlük sürede $35^{\circ} \mathrm{C}$ 'de karanlıkta bekletilerek sicaklık uygulaması ve su içinde kültüre alınmasıyla şeker açlığı uygulaması beraber uygulanmıștır [22-24]. Daha sonra mikrosporlar ilk olarak Miyoshi [22] tarafından belirtilen ve patlıcanda mikrospor kültüründen kallus elde edilen tek ortam olan; \%2 sakkaroz, $0.5 \mathrm{mg} / \mathrm{l}$ naphthaleneacetic acid (NAA) ve $0.5 \mathrm{mg} / \mathrm{l}$ 6benzylaminopurine (BAP) içeren NLN ortamında $(\mathrm{pH}$ 5.9) kültüre alınmıştır. Kültüre alınan petri kapları $25^{\circ} \mathrm{C}^{\prime}$ de bir ay boyunca karanlıkta inkübe edilmiștir.

Kültüre alınan mikrosporların canlılığını test etmek amaciyla fluorescein diacetate (FDA) ile boyama yöntemi kullanılmıştır. Bu amaçla mikrosporlar kültüre alındıktan hemen sonra ve 3 günlük sıcaklık uygulamasının ardından FDA ile boyanarak mikrosporların canlılıkları incelenmiştir. Çekirdek bölünmeleri ve embriyogenik gelişim gösteren mikrosporları incelemek amacıyla 4',6-diamidino-2phenylindole (DAPI) boyama yöntemi kullanılmıştır. $\mathrm{Bu}$ amaçla mikrospor süspansiyonundan $200 \mu \mathrm{l}$ alınarak $8000 \mathrm{rpm}$ de 2 dakika santrifüjlendikten 
sonra elde edilen mikrospor peletine $10 \mu \mathrm{l}$ DAPI solüsyonu eklenmiş ve flouresans mikroskop altında inceleme yapılmıştır [31].
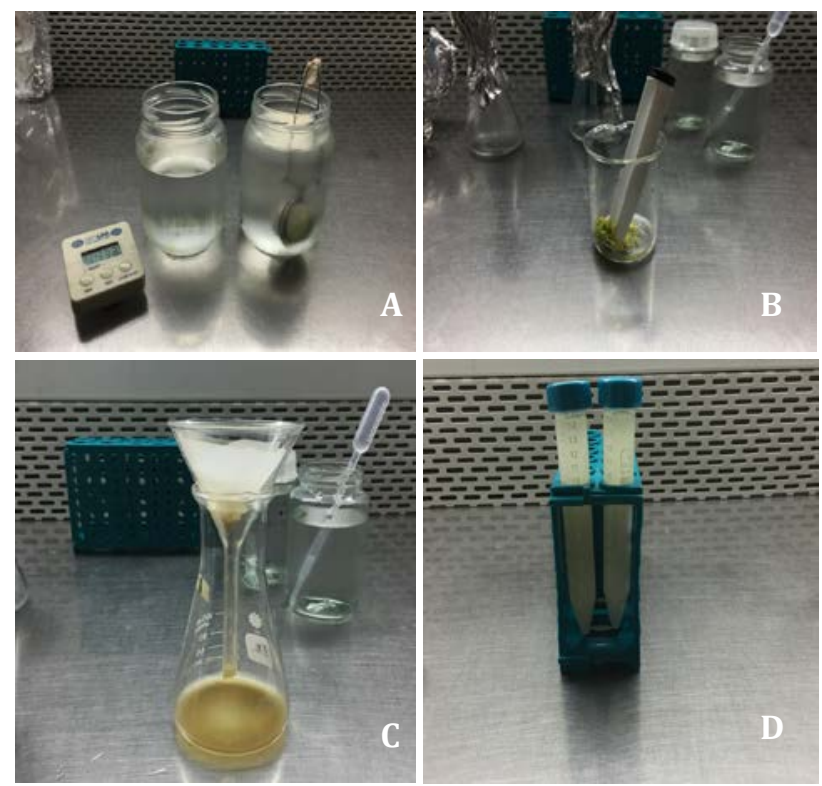

Şekil 1. Mikrosporların anterlerden izolasyonu. a. Kabin içerisinde anterlerin sterilizasyonun yapılışı. b. Mikrospor izolasyonu amaciyla anterlerin ezilmesi. c. Anter dokularının uzaklaştırılması amacıyla mikrospor süspansiyonunun süzülmesinde kullanılan $40 \mu \mathrm{m}$ filtre sistemi. d. Mikrospor peleti elde etmek amaciyla santrifüj tüplerine alınan mikrospor süspansiyonu.

\section{Bulgular ve Tartışma}

$\mathrm{Bu}$ çalışmada iki adet patlıcan çeşidinde mikrospor kültürü çalışması yapılmıştır. Mikrospor kültürü çalışmalarında ilk aşama, en uygun dönemdeki mikrosporları içeren anterlerin belirlenmesidir. $\mathrm{Bu}$ bağlamda, ilk polen mitozu etrafında dönen mikrosporların/polenlerin embriyogenesise doğru saptırmak için en uygun aşamada olduğu hakkında geniş bir görüş birliği vardır [32, 33]. Diğer bir deyişle, bu aşamaların vakuol mikrospor ve genç çift çekirdekli polen aşamaları olduğuna inanılmaktadır. $\mathrm{Bu}$ çalışmada da mikrospor kültürünün yapıldığı aşamada kültüre alınan mikrosporların çoğunluğu vakuol mikrospor veya genç çift çekirdekli polen aşamasındadır (Şekil 2a).

Kültüre alınan mikrosporlarda canlılık önemli bir konu olup; bu çalışmada da kullanılan iki farklı çeşidin mikrospor canlılıkları FDA ile boyanarak tespit edilmiştir (Sekil 21). Canlı olan mikrosporlar flouresans ışık altında parlak görünmektedir. Bizim çalışmamızda canlılık mikrosporların izolasyonundan hemen sonra ve stres uygulamasının sonunda test edilmiştir. Mikrosporların kültüre alındığı andaki sonuçlara göre G07-1 çeşidinde mikrosporların $\% 35.90$, stres uygulaması sonunda ise \%16.08 oranında canlı olduğu saptanmıştır. Diğer çeşitte ise kültüre alındığı anda mikrosporların \%28.44'nin, stres uygulaması sonunda ise \%22.01 oranında canlı olduğu tespit edilmiştir.
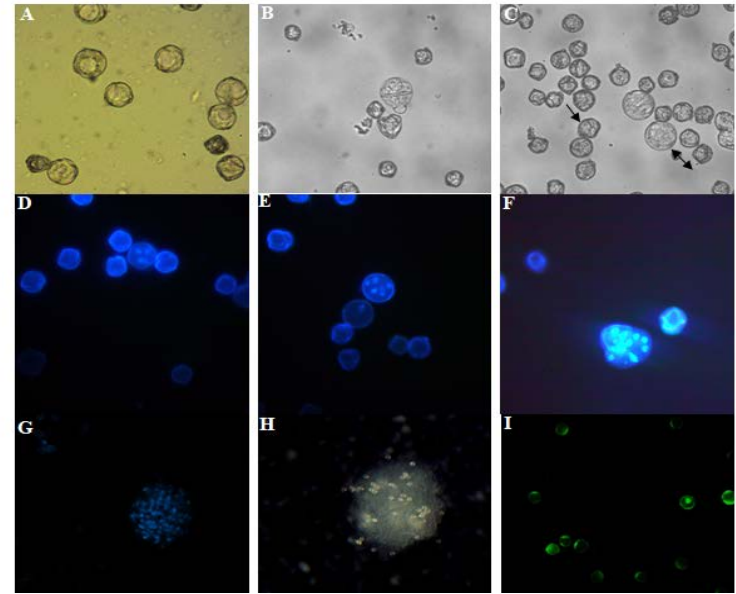

Şekil 2. Patlıcanda mikrospor kültürü. a. Kültüre alınan mikrosporlar. b. Sporofitik gelişim gösteren mikrosporlarda simetrik bölünme. c. Normal gametofitik gelişim gösteren polen ( $\boldsymbol{Q}$ ) ve gelişimlerini durduran mikrosporlar $(\boldsymbol{V})$. d. Dört çekirdekli mikrosporlar e. Altı çekirdekli mikrosporlar. f-g. Çok çekirdekli yapılar. $\mathrm{h}$. Kallus benzeri yapılar. l. FDA ile boyanmış canlı mikrosporların flouresans mikroskop altındaki görüntüsü.

Mikrospor kültürü yoluyla mikrosporların tüm gelişim süreci ışık ve flouresans mikroskobu altında incelenmiştir. Gelişim sürecinin kullanılan çeşitlerin her ikisinde de aynı olduğu tespit edilmiştir. Stres uygulamalarına maruz kalan mikrosporlardan birçoğu hemen gelişimini durdurur ve/veya ölürken; herhangi bir morfolojik değişim göstermemiş ve başlangıçta kültüre alındığı halde kalmıştır (Şekil 2c). Bazları ise olgun poleni meydana getirmek üzere gametofitik gelişimi takip etmişlerdir (Şekil 2c). Diğer bazı mikrosporların ise stres uygulamaları ile etkili bir biçimde bölünmeleri uyarılmıștır. $\mathrm{Bu}$ mikrosporlarda stres uygulamasından beș gün sonra bazı mikrosporların sporofitik gelişiminin başlangıç göstergelerinden biri olduğu kabul edilen simetrik olarak bölündükleri gözlenmiştir (Şekil 2b). Stres uygulamasının ardından $25^{\circ} \mathrm{C}$ de bekletildiği kültürün ilk haftasında dört ve daha fazla hücreli mikrosporlar belirlenmiş (Şekil $2 \mathrm{~d}$-e) ve yaklaşık 10 gün sonra çok hücreli yapılar meydana gelmiştir (Şekil 2f). İlk dört hafta boyunca bu çok hücreli yapılarla birlikte düzensiz kallus benzeri yapılar gözlenmeye başlanmıştır (Şekil 2h). Daha sonraki süreçte herhangi bir embriyo oluşumu gözlemlenmemiştir. Araștırmada bir ay sonunda mikrosporlardan yalnızca kallus oluşumu meydana gelmiştir. G07-1 çeşidinde ortalama 288 kallus /petri elde edilirken diğer çeşitte 64 kallus/petri meydana gelmiştir.

Patlıcanda yapılan önceki mikrospor kültürü çalışmalarına paralel olarak mikrosporlardan kallus meydana geldiği tespit edilmiştir [22-24]. Bu durum genel olarak androgenik sistemlerin çoğunluğuyla ilgili bilinenlerle karşılaştırıldığında; normalde mikrosporların embriyo üretmek üzere indüklenmesi beklenirken kallus oluşumu yoluna giderek farklı bir gelişim takip ettiğini göstermektedir. Buna göre, patlıcan dahil, anter kültüründen mikrosporlar 
embriyo oluşturur ve kallus çoğunlukla anterlerdeki somatik dokularından kaynaklanır. Mikrospor kültüründe ise somatik dokular uzaklaştırıldığından dolayı, kallusların kökeninin mikrosporlar olduğu sonucuna varabiliriz.

$\mathrm{Bu}$ nedenle patlıcanda mikrosporların neden bu kadar farklı davrandığı sorusu ortaya çıkmaktadır. Bu soruya ışık tutmak için, androgenesisde mikrospor indüksiyonunun ilk aşamaları ışık ve flouresans mikroskobunda incelenmiştir. Doğrudan embriyogenesise gitmek üzere genetiksel olarak programlanmış olan mikrosporlar; embriyo haline gelmek için farklı seviyelerde birçok değişikliğe maruz kalmaktadırlar. Bu değişiklikler çerçevesinde, mikrosporlar önemli ölçüde büyür, hücre merkezine doğru çekirdek yeniden konumlanır, sitoplazma belirginleşir ve büyük vakuol küçük parçalara ayrılır [32]. Bu düzenlemeler birçok türde indüklenen mikrosporlarda embriyogenik gelişimin geçici ve erken morfolojik işareti olarak kabul edilmektedir $[34,35]$. Diğer bir morfolojik gösterge ise androgenesis indüksiyonunda çekirdeğin yeniden konumlanmasının ardından gözlenen simetrik bölünmelerdir [36]. Bu çalışmada da kullanılan çeşitlerde stres uygulamasıyla birlikte simetrik bölünmenin meydana gelmesi ve çok çekirdekli yapıların oluşumuyla her iki çeşitte de bazı mikrosporların sporofitik gelişime doğru yönlendiği gözlemlenmiştir (Şekil 2b-f).

Önceki yıllarda yapılan bazı çalışmalarda stres uygulamasına maruz kalmasıyla bölünmeleri uyarılan mikrosporların ya doğrudan embriyogenesise yöneldiği ya da bazı durumlarda genotipe bağlı olarak çok hücreli kallus benzeri yapılar meydana getirdiği ve bunlardan uygun koşullar altında organogenesis yoluyla haploid veya DH bitkiler üretmenin mümkün olduğu bildirilmiştir [23, 24]. Mikrosporlardan doğrudan embriyo elde edilen türlere örnek olarak mikrospor embriyogenesis için model sistem olarak tanımlanan kolza, arpa, tütün veya buğday gibi türler gösterilmektedir [6]. Mikrosporlardan meydana gelen kalluslardan elde edilen DH bitkilere örnek birçok türde bildirilmiştir [4]. Mevcut araştırmada da bir ayın sonunda mikrosporlardan yalnızca kallus oluşumu meydana gelmiştir ve doğrudan embriyogenesis meydana gelmemiştir. Ayrıca yapılan mikroskobik incelemelerde mikrosporların doğrudan kallusa dönüşmediği belirlenmiştir. Mikrospor kültür sürecinin detaylı çalışılması neticesinde, indüksiyondan hemen sonra patlıcan mikrosporlarının embriyogenesisin başlangıç aşamasına girdiği mevcut araştırmada gözlenmiştir. Elde edilen bu sonuç önceki çalışmalarla uyum içerisindedir.

\section{Sonuç}

Mikrospor kültürü ile yapılan çalışmalar genelde son yıllarda artmış olmakla birlikte, yeni protokollerin geliștirilmesine ve standart hale getirilmesine halen ihtiyaç duyulmaktadır. Burada vurgulanması gereken önemli noktalardan biri de ülkemizde özellikle ekonomik olarak önemli bitkilerde sınırlı sayıda araştırma bulunan mikrospor kültürüne yönelik araştırmalardır. Geliştirilecek olan metotların ıslah programlarında farklı genotipler için rutin olarak uygulanacak etkin ve güvenilir bir teknoloji haline getirilmesi gerekmektedir. Bu amaçla bundan sonraki çalışmalarda bu araştırmada belirtilen protokolün geliştirilmesi veya yeni protokollerin oluşturulması için mikrospor kültürü için farklı ortam kombinasyonlarının ve farklı stres uygulamalarının denenmesi faydalı olacaktır. Böylece verimli ve gelecek vaat eden bir teknik olan mikrospor kültürü üzerine yapılan çalışmalarda önemli bir boşluk doldurulmuş olacak ve ülkemizde eksik bulunan mikrospor kültürü çalışmaların sayısının artmasına ve bu yöntemin geliştirilmesine bu araștırmanın katkı sağlayacağı düşünülmektedir.

\section{Kaynakça}

[1] Forster, B.P., Herberle-Bors, E., Kasha, K.J., Touraev, A. 2007. The resurgence of haploids in higher plants. Trends in Plant Science, 12(8), 368-375.

[2] Dunwell, J.M. 2010. Haploids in flowering plants: origins and exploitation. Plant Biotechnol J., 8: 377-424.

[3] Germanà, M. 2011. Gametic embryogenesis and haploid technology as valuable support to plant breeding. Plant Cell Rep., 30: 839-857.

[4] Segui-Simarro, J.M. 2010. Androgenesis revisited. The Botanical Review., 76: 377-404.

[5] Maluszynski, M., Kasha, K.J., Szarejko, I. 2003. Published doubled haploid protocols in plant species. pp 309-335. Maluszynski, M., Kasha, K.J., Forster, B.P., Szarejko, I. eds. 2003. Doubled haploid production in crop plants A manual. Kluwer Academic Publishers, Dordrecht, Netherlands, 428.

[6] Maraschin, S.F., De-Priester, W., Spaink, H.P., Wang, M. 2005. Androgenic switch: an example of plant embryogenesis from the male gametophyte perspective. J Exp Bot., 56: 17111726.

[7] Segui-Simarro, J.M., Corral-Martinez, P., ParraVega, V., Gonzalez-Garcia, B. 2011. Androgenesis in recalcitrant Solanaceous crops. Plant Cell Rep., 30: 765-778.

[8] Raina, S.K., Iyer, R.D. 1973. Differentiation of diploid plants from pollen callus in anther cultures of Solanum melongena L. Z Pflanzenzucht, 70: 275-280.

[9] Isouard, G., Raquin, C., Demarly, Y. 1979. Obtention de plantes haploides et diploides par 
culture in vitro d'anthères dáubergine (Solanum melongena L.). C R Acad Sci, Paris, 288: 987-989.

[10] Dumas de Vaulx, R., Chambonnet, D. 1982. Culture in vitro d'anthères d'aubergine (Solanum melongena L.): stimulation de la production de plantes au moyen de traitements à $35^{\circ} \mathrm{C}$ associés à de faibles teneurs en substances de croissance. Agronomie, 2: 983988.

[11] Misra, N.R., Varghese, T.M., Maherchandani, N., Jain, R.K. 1983. Studies on induction and differentiation of androgenic callus of Solanum melongena L. pp 465-468. Sen, S.K., Giles, K.L. eds. 1983. Plant cell culture in crop improvement. Plenum Press, New York, 502p.

[12] Borgel, A., Arnaud, M. 1986. Progress in eggplant breeding, use of haplomethod. Capsicum Newsl, 5:65-66.

[13] Rotino, G.L., Falavigna, A., Restaino, F. 1987. Production of anther-derived plantlets of eggplant. Capsicum Newsl, 6:89-90.

[14] Tuberosa, R., Sanghineti, M.C., Conti, S. 1987. Anther culture of eggplant Solanum melongena L. lines and hybrids. Gene'tica Agra'ria, 41:267274.

[15] Rotino, G.L. 1996. Haploidy in eggplant. pp 115141. Jain, S.M., Sopory, S.K., Veilleux, R.E. eds. 1996. In vitro haploid production in higher plants, Kluwer Academic Publishers, Dordrecht, The Netherlands, 412p.

[16] Rotino, G.L., Sihachakr, D., Rizza, F., Vale, G., Tacconi, M.G., Alberti, P., Mennella, G., Sabatini, E., Toppino, L., D'Alessandro, A., Acciarri, N. 2005. Current status in production and utilization of dihaploids from somatic hybrids between eggplant (Solanum melongena L.) and its wild relatives. Acta Physiol Plant, 27: 723733.

[17] Alpsoy, H.C., Seniz, V. 2007. Researches on the in vitro androgenesis and obtaining haploid plants in some eggplant genotypes. Acta Hortic, 729:137-141.

[18] Salas, P., Prohens, J., Segur'-Simarro, J.M. 2011. Evaluation of androgenic competence through anther culture in common eggplant and related species. Euphytica, 182:261-274.

[19] Salas, P., Rivas-Sendra, A., Prohens, J., SeguiSimarro, J.M. 2012. Influence of the stage for anther excision and heterostyly in embryogenesis induction from eggplant anther cultures. Euphytica, 184:235-250.

[20] Başay, S., Ellialtıŏlu, Ş. 2012. Effect of genotypical factors on the effectiveness of anther culture in eggplant (Solanum melongena L.). Turk J Biol, 37: 499-505.
[21] Gu, S.R. 1979. Plantlets from isolated pollen cultures of eggplant (Solanum melongena L.). Acta Bot Sin, 21: 30-36.

[22] Miyoshi, K. 1996. Callus induction and plantlet formation through culture of isolated microspores of eggplant (Solanum melongena L.). Plant Cell Rep, 15:391-395.

[23] Corral-Martinez, P., Segui-Simarro, J.M. 2012. Efficient production of callus-derived doubled haploids through isolated microspore culture in eggplant (Solanum melongena L.). Euphytica, 187:47-61.

[24] Corral-Martinez, P., Segui-Simarro, J.M. 2014. Refining the method for eggplant microspore culture: effect of abscisic acid, epibrassinolide, polyethylene glycol, naphthaleneacetic acid, 6benzylaminopurine and arabinogalactan proteins. Euphytica, 195: 369-382.

[25] Bal, U., Abak, K. 2005. Induction of Symmetrical Nucleus Division and Multicellular Structures from the Isolated Microspores of Lycopersicon Esculentum Mill. Biotechnology \& Biotechnological Equipment, 19(1): 35-42.

[26] Bal, U., Ellialtioglu, S., Abak, K. 2009. Induction of symmetrical nucleus division and multi-nucleate structures in microspores of eggplant (Solanum melongena L.) cultured in vitro. Sci Agric. 66: 535-539.

[27] Tuncer, B., Yanmaz, R. 2011a. Effects of colchicine and high temperature treatments on isolated microspore culture in various cabbage (Brassica oleraceae) types. International Journal of Agriculture and Biology, 13(5): 819-822.

[28] Tuncer, B., Yanmaz, R. 2011b. Induction of microspore embryogenesis in ornamental kale by gamma irradiation and high temperature stress. Asian Journal of Biotechnology, 3: 415421.

[29] Tuncer, B., Cig, A., Yanmaz, R., Yasar, F. 2016. Effect of heat shock treatment on microspore embryogenesis in Brassica oleracea species. Journal of Agricultural Scieces, 22(4): 548-554.

[30] Tuncer, B. 2017. Callus formation from isolated microspore culture in radish (Raphanus sativus L.). The Journal of Animal \& Plant Sciences, 27(1): 277-282.

[31] Custers, J.B.M. 2003. Microspore culture in rapeseed (Brassica napus L.). pp 185-194. Maluszynski, M., Kasha, K.J., Forster, B.P., Szarejko, I. Eds. 2003, Doubled haploid production in crop plants: a manual. Kluwer Academic Publishers, Dordrecht, Netherlands, 428.

[32] Touraev, A., Pfosser, M., Heberle-Bors, E. 2001. The microspore: a haploid multipurpose cell. Adv Bot Res, 35:53-109. 
[33] Segui-Simarro, J.M., Nuez, F. 2008. How microspores transform into haploid embryos: changes associated with embryogenesis induction and microspore-derived embryogenesis. Physiologia Plantarum, 134: 112.

[34] Indrianto, A., Barinova, I., Touraev, A., HeberleBors, E. 2001. Tracking individual wheat microspores in vitro: identification of embryogenic microspores and body axis formation in the embryo. Planta, 212: 163-174.
[35] Maraschin, S.F., Vennik, M., Lamers, G.E.M., Spaink, H.P., Wang, M. 2005. Time-lapse tracking of barley androgenesis reveals positiondetermined cell death within pro-embryos. Planta, 220: 531-540.

[36] Zaki, M.A.M., Dickinson, H.G. 1991. Microsporederived embryos in Brassica: the significance of division symmetry in pollen mitosis I to embryogenic development. Sexual Plant Reproduction, 4:48-55. 